\title{
Increased Immunoglobulin Response to $\gamma$-Interferon by Lymphocytes from Patients with Systemic Lupus Erythematosus
}

\author{
Joseph Golbus, Michael Salata, Jay Grefnwood, Jerry Hudson, and \\ BRUCE C. RICHARDSON ${ }^{1}$
}

Division of Rheumatology, Department of Internal Medicine, and the Department of Pathology, University of Michigan Medical Center, Ann Arbor, Michigan, 48109

\begin{abstract}
The factors responsible for abnormal B-cell activation in systemic lupus erythematosus (SLE) are incompletely understood. This study tested the hypothesis that the abnormal B-cell activation observed in human SLE may be due to an augmented response to a helper signal. We demonstrated that non-T cells from 10 of 19 SLE patients increased IgG production in response to interferon- $\gamma$ (IFN- $\gamma$ ) by a mean factor of $20.9 \pm$ 3.9 over resting levels, while controls stimulated a mean factor of $3.0 \pm 0.5(P<0.005)$. We found no relationship of IFN- $\gamma$ responsiveness to disease activity. Serotyping for HLA A, B, C, and D loci suggested that the hyperresponsiveness may be genetically linked to HLA-Cw7. We conclude that IFN- $\gamma$ may contribute to the development and perpetuation of SLE in a subset of patients with SLE. 1988 Academic Press. Inc.
\end{abstract}

\section{INTRODUCTION}

Systemic lupus erythematosus (SLE) is a chronic inflammatory disease characterized by multiple immunologic abnormalities including B lymphocyte hyperactivity. This hyperactivity is manifested by increased numbers of circulating antibody-forming cells, polyclonal hypergammaglobulinemia, and autoantibody production (1-3). Although factors responsible for the abnormal B-cell activation are incompletely understood, potential immunoregulatory defects which might contribute include T-helper-cell hyperactivity, T-suppressor-cell dysfunction, and regulatory abnormalities leading to an increased responsiveness to helper signals or a decreased responsiveness to suppressor signals. No consistent abnormalities of T-cell function have been demonstrated in human SLE. Several studies suggested absent or reduced suppressor cell function as a primary factor in the pathogenesis of SLE (4-7). However, subsequent reports have described normal suppressor T-cell activity $(8,9)$.

Polyclonal B-cell hyperactivity has also been demonstrated to be a common feature of the SLE-like illness that develops in a variety of genetically predisposed strains of mice. Theofilopoulos, Dixon, and colleagues have demonstrated that the New Zealand black/white (NZB/W) and BXSB mouse strains display excessive B-cell proliferation and differentiation in response to in vitro lympho-

\footnotetext{
1 Address reprint requests to Bruce C. Richardson, M.D., Ph.D., Department of Medicine, Division of Rheumatology, 3918 Taubman Center, Box 0358, Ann Arbor, MI 48109-0358.
} 
kine challenges and activation signals (10). Thus, in murine models of SLE, increased responsiveness of $B$ cells to helper signals may lead to the B-cell hyperactivity fundamental to the disease.

The present study tests the hypothesis that human SLE may be due in part to an increased immunoglobulin response to a helper factor. Interferon- $\gamma($ IFN- $\gamma$ ) is a T-cell-derived lymphokine that can act as a B-cell differentiation factor (BCDF) $(11,12)$. Furthermore, IFN- $\gamma$ has been shown to accelerate autoimmune disease in murine models of SLE (13-15), and purified recombinant IFN- $\gamma$ is now available. For these reasons we selected IFN- $\gamma$ as a model lymphokine for studying immunoglobulin responses in SLE. The results demonstrate that a subset of human SLE patients have lymphocytes which hyperrespond to IFN- $\gamma$ and which may resemble the NZB/W model of SLE.

\section{PATIENTS AND METHODS}

Study sample. SLE subjects were selected from the rheumatology clinic population and in-patient rheumatology service at the University of Michigan. All subjects fulfilled at least four criteria for the classification of SLE, as defined by the American Rheumatism Association (16). Clinical activity was scored according to the method of Barada et al. (17), where $O=$ complete remission, $1=$ mild activity, 2 = moderate activity, and 3 = severe systemic disease. Subjects on more than $5 \mathrm{mg}$ per day of prednisone or its equivalent were excluded from study to avoid the redistribution effects of corticosteroids on circulating lymphocyte subpopulations. Similarly, subjects being treated with cytotoxic agents were excluded. The control population consisted of healthy volunteers.

Isolation of lymphocytes. Peripheral blood mononuclear cells (PBMC's) were prepared from heparinized venous blood as previously described $(18,19)$. T cells were depleted by rosetting with sheep erythrocytes treated with $4 \%$ 2-aminoethylisothiouronium bromide hydrobromide (AET, Sigma, St. Louis, MO) as described elsewhere (20). This procedure routinely gives $93 \%$ rosette-positive cells in the rosetted population and $2 \%$ rosette-positive cells in the B-cell-enriched or non-T population. Conversely, the number of surface immunoglobulin-positive cells in the rosetted, T-enriched population is usually $3 \%$, while the number of immunoglobulin-positive cells in the nonrosetting population is approximately $50 \%$. Where indicated, monocytes were depleted by adherance to $60-\mathrm{mm}$ plastic petrie dishes (Nunc) (19). A quantity of $10^{7} \mathrm{PBMCs}$ was incubated in $5 \mathrm{ml} \mathrm{RPMI}$ containing $10 \%$ fetal bovine serum (FBS) (HyClone, Logan, UT) at $37^{\circ} \mathrm{C}$ for $1 \mathrm{hr}$ and then transferred to a second petrie dish and the incubation was repeated to further deplete adherent cells. The B-enriched populations were cultured at 1.25 $\times 10^{5}$ per well in flat-bottomed 96-well microtiter plates (InterMed-Nunc) in 200 $\mu l$ of medium containing RPMI 1640 supplemented with $10 \%$ FBS, penicillin ( 100 $\mathrm{IU} / \mathrm{ml}$ ), streptomycin $(100 \mu \mathrm{g} / \mathrm{ml})$, and $5 \times 10^{-5} M 2$-mercaptoethanol (Sigma). The FBS is characterized by the manufacturer (HyClone) and contains less than $10 \mathrm{ng} / \mathrm{ml}$ endotoxin. Purified IFN- $\gamma$ (Genentech, San Francisco, CA) was added in concentrations of $10^{3}, 10^{2}$, and 10 units per well. Cultures were incubated at $37^{\circ} \mathrm{C}$ in a $95 \%$ air, $5 \% \mathrm{CO}_{2}$ humidifed atmosphere. After 4 days, the microtiter plates were centrifuged at $4^{\circ} \mathrm{C}$ for $5 \mathrm{~min}$ at $50 \mathrm{~g}$, the culture supernatants were 
aspirated, and fresh medium was added. The cultures were incubated an additional 6 days and centrifuged, and the cell-free supernatants were harvested. Quadruplicate cultures were pooled for assay.

Assay for immunoglobulin production by enzyme-linked immunoabsorbent assays (ELISA). Total IgG and IgM were quantitated by an ELISA method (21). Immulon plates of 96 wells (InterMed-Nunc) were coated with $3.5 \mu \mathrm{g}$ of goat anti-human IgM or $5.0 \mu \mathrm{g}$ of goat anti-human IgG (Cappel Laboratores, Inc., Westchester, PA) in $100 \mu$ l of a $0.05 M$ carbonate buffer, $\mathrm{pH} 9.6$, for $18 \mathrm{hr}$ at $4^{\circ} \mathrm{C}$. The wells were washed three times with phosphate-buffered saline-0.05\% Tween 20 (J. T. Baker Chemical Co., Phillipsburg, NJ), pH 7.2 (PBS-Tween). To block any unbound sites on the plastic, the wells were incubated at room temperature for $3 \mathrm{hr}$ with $200 \mu \mathrm{l}$ of $5 \%$ bovine serum albumin (BSA) (Sigma) in PBS-Tween. The BSA-PBS-Tween solution was removed and $100 \mu$ l of culture supernatant dilutions or appropriate dilutions of standards was added and incubated for $18 \mathrm{hr}$ at $4^{\circ} \mathrm{C}$. All experimental samples and standards were assayed in quadruplicate. The plates were then washed three times with $1 \%$ BSA in PBS-Tween. One hundred microliters of a 1:1000 dilution of horseradish peroxidase-conjugated goat anti-human immunoglobulin (Sigma) in 1\% BSA in PBS-Tween was added. The plates were incubated at $4^{\circ} \mathrm{C}$ for $2 \mathrm{hr}$ and then washed three times with $1 \%$ BSA in PBS-Tween. One hundred microliters of a developing solution consisting of $0.2 M$ potassium phosphate, $0.003 \% \mathrm{H}_{2} \mathrm{O}_{2}, 0.1 \%$ Triton $\mathrm{X}-100$, and $10 \mathrm{mg} \%$ $O$-dianisidine (Sigma) was added to each well. Color development was arrested after $30 \mathrm{~min}$ with $100 \mu \mathrm{l}$ of $50 \% \mathrm{H}_{2} \mathrm{SO}_{4}$ and the color was measured at $530 \mathrm{~nm}$ using a Titertek Multiscan multichannel spectrophotometer.

Standard curves were generated for each experiment using dilutions of affinitypurified IgM myeloma protein (Cappel) and Cohn fraction II human immunoglobulin (Sigma). Only dilutions of experimental samples that gave optical density readings within the linear portion of the standard curves were analyzed.

Analysis of lymphocyte populations with a fluorescein-activated cell sorter $(F A C S)$. Cytofluorographic analyses of cell populations were performed by indirect immunofluorescence with fluorescein isothiocyanate (FITC)-conjugated antibodies to B1 (Coulter Immunology, Hialeah, FL), phycoerythrin-conjugated antiIL2 receptor (Coulter), and FITC-conjugated anti-human Ig (Coulter) using a modification of procedures previously described (22).

Tissue typing. HLA typing for antigens at the A, B, and C loci of the major histocompatibility complex was performed by the Tissue Typing Laboratory at the University of Michigan, using the microdroplet lymphocytotoxicity method on mononuclear cells (23). Typing for HLA-DR antigens was performed on B lymphocytes isolated on nylon wool columns (24). Antisera included reagents from the 8th International Histocompatibility Workshop (8w) (25). Tissue typing was performed on freshly isolated cells or on cells that had been previously frozen. In all cases, adequate numbers of B cells were obtained.

Statistical analysis. $P$ values between the means of groups of data were calculated using Student's $t$ test. Associations between response to IFN- $\gamma$ and HLACw7 were determined by $\chi^{2}$ analysis with the Yates correction and a relative risk computation. 


\section{RESULTS}

Response of control and SLE lymphocytes to IFN- $\gamma$. Preliminary experiments were performed to optimize the immunoglobulin response to IFN- $\gamma$. In these studies IFN- $\gamma$ was added to cultures of T-depleted cells to avoid the effects of IFN- $\gamma$ on helper- and suppressor-T-cell activity $(26,27)$. Dose-response curves, generated for the majority of the patients and controls, demonstrated that most subjects responded optimally to 1000 units of IFN- $\gamma$, although four individuals were stimulated optimally with 100 units of IFN- $\gamma$ per well (data not shown).

Total IgG levels were determined for cells cultured with and without IFN- $\gamma$ to assess whether non-T cells from SLE patients respond to IFN- $\gamma$ with increased IgG synthesis compared to controls. Resting and activated IgG production is plotted for individuals with SLE and controls in Fig. 1. The stimulation index (activated/resting IgG synthesis) is reflected by the slopes from resting to stimulated values. The first group (hyperresponders) has stimulation indexes at least 2 standard deviations greater than the mean of control values. The second, normalresponding, SLE group had elevated resting levels of IgG synthesis, but stimulation indexes similar to that of controls. In Table 1, the mean concentration of IgG produced by the three groups are compared. Subjects with SLE demonstrated an increased resting synthesis of IgG. Nineteen patients with SLE had a mean resting IgG production of $53 \pm 17 \mathrm{ng} / \mathrm{ml}$ (mean $\pm \mathrm{SEM}$ ). Twelve controls produced a mean of $13 \pm 3 \mathrm{ng} / \mathrm{ml} \mathrm{IgG}$ at rest. When responses to IFN- $\gamma$ were compared, 10 patients with SLE had a mean stimulation index of $20.9 \pm 3.9$, while controls had a mean stimulation index of $3.0 \pm 0.5(P<0.005)$. The remaining 9 patients with SLE had a mean stimulation index of $2.3 \pm 0.6$. Importantly, the unstimulated IgG production by both lupus groups was similar $(40 \pm 20$ vs $66 \pm$ 28 ), indicating that both groups contained comparable numbers of preactivated $B$ cells. These data demonstrate that a subset of patients with SLE has non-T lymphocytes which respond to IFN- $\gamma$ with increased synthesis of IgG compared to controls, and that B-cell preactivation as measured by unstimulated IgG synthesis is not responsible for the difference.

Two recent reports demonstrate that IFN- $\gamma$ can act directly on preactivated, interleukin- 2 receptor (IL-2R)-bearing cells to induce Ig synthesis $(28,29)$. To test whether the hyperresponsive subset contained larger numbers of IL-2R-bearing $B$ cells, PBMCs from four hyperresponsive patients, three normal-responding patients, and three normal controls were stained with B1-FITC and phycoerythrinconjugated anti-IL-2R monoclonal antibodies, and then were analyzed by twocolor flow cytometry. Only one subject in each lupus group had more IL-2Rbearing $\mathrm{B}$ cells than did the normal controls (data not shown), further indicating that $\mathrm{B}$-cell preactivation is not responsible for the observed differences in the response to IFN- $\gamma$.

As with IgG, SLE patients also demonstrated increased resting synthesis of IgM. Mean resting IgM synthesis in 19 SLE patients was $270 \pm 137 \mathrm{ng} / \mathrm{ml}$. Mean resting IgM synthesis in 12 controls was $131 \pm 44 \mathrm{ng} / \mathrm{ml}$. In addition, IgM production in response to IFN- $\gamma$ was increased in the same subset of 10 lupus patients relative to the two other groups, although there was more variation among indi- 


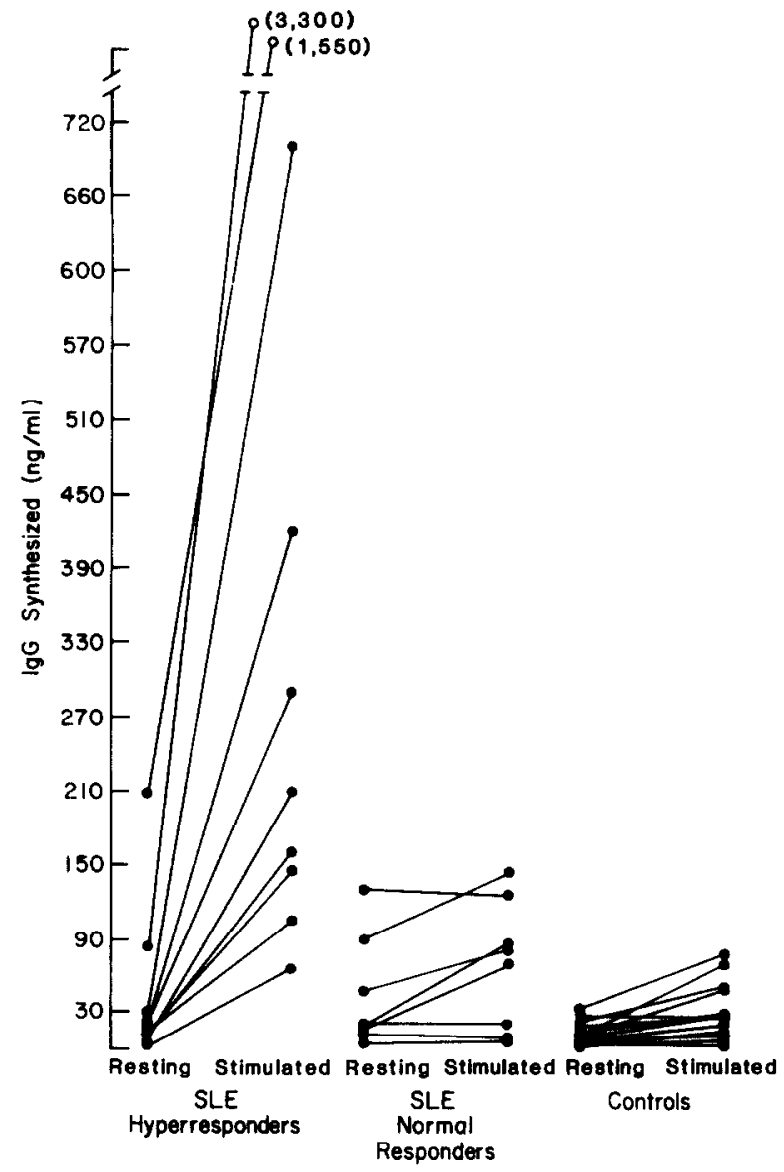

FIG. 1. IgG synthesis of B-enriched lymphocyte preparations at rest and in response to IFN- $\gamma .1 .25$ $\times 10^{5}$ B-enriched lymphocytes were cultured in $0.2 \mathrm{ml} \mathrm{RPMI}, 10 \%$ fetal bovine serum, and $5 \times 10^{-5}$ $M$ 2-mercaptoethanol. Cells were cultured with and without IFN- $\gamma, 0.5 \times 10^{2}-0.5 \times 10^{4}$ units $/ \mathrm{ml}$. Fresh media was added on Day 4 and supernatants were harvested 6 days later. All cultures were performed in quadruplicate and supernatants were pooled. Total IgG secreted was measured by an ELISA technique. The first group (hyperresponders) have stimulation indexes (activated/resting IgG synthesis) at least 2 standard deviations greater than the mean of control values.

viduals in each group. Table 2 summarizes these results. The hyperresponding subset of SLE patients had an IgM stimulation index of $39.4 \pm 29.1$. The remaining 9 SLE patients had an IgM stimulation index of $4.2 \pm 2.6$, similar to the control value of $3.7 \pm 1.5$. These data demonstrate that a subset of SLE patients responds to IFN- $\gamma$ with increased synthesis of IgM as well as IgG compared to controls.

Comparison of response to IFN- $\gamma$ with number of $B$ lymphocytes. The numbers of B lymphocytes in lupus and control PBMCs were compared by flow cytometry to assess whether increased numbers of $B$ lymphocytes were responsible for the increased immunoglobulin response to IFN- $\gamma$. B-cell numbers were estimated by 
TABLE 1

IgG Synthesis of B-EnRiched Lymphocyte PREPaRations at Rest and in ReSPONSE to IFN- $\gamma$

\begin{tabular}{cccc} 
& \multicolumn{3}{c}{$\begin{array}{c}\text { IgG concentration in } \\
\text { culture supernatants }(\mathrm{ng} / \mathrm{ml})^{a}\end{array}$} \\
Subjects $(n)^{b}$ & Resting & Stimulated & Stimulation index \\
\hline SLE (19) & $53 \pm 17^{e}$ & $444 \pm 182$ & $12.1 \pm 3.0$ \\
Group A (10) & $40 \pm 20$ & $694 \pm 294$ & $20.9 \pm 3.9^{c}$ \\
Group B (9) & $66 \pm 28$ & $167 \pm 100$ & $2.3 \pm 0.6$ \\
Control (12) & $13 \pm 3$ & $32 \pm 7$ & $3.0 \pm 0.5$ \\
\hline
\end{tabular}

a $1.25 \times 10^{5}$ B-enriched cells were cultured in $0.2 \mathrm{mI} \mathrm{RPMI}, 10 \%$ fetal bovine serum, and $5 \times 10^{-5}$ $M$ 2-mercaptoethanol, with and without IFN- $\gamma, 0.5 \times 10^{2}-0.5 \times 10^{4} \mathrm{u} / \mathrm{ml}$. Fresh media was added on Day 4 and supernatants were harvested 6 days later. All cultures were performed in quadruplicate, and supernatants were pooled. Total IgG secreted was measured by an ELISA technique. Results are expressed as the mean \pm SEM of quadruplicate ELISA assays. Maximum IgG resonses are reported.

${ }^{b} n$ represents the number of subjects tested.

c $P<0.005$ (Student's $t$ test) relative to controls.

${ }^{d}$ Stimulation index is the ratio of IgG produced by stimulated/resting cells.

e $P<0.05$ (Student's $t$ test) relative to controls.

determining the number of cells bearing the surface antigen B1, as well as the number of cells bearing Ig (Table 3 ). While there was a slight increase in the number of cells bearing the B1 antigen in the SLE group, the difference was not statistically significant and cannot account for the variations in response to IFN- $\gamma$ observed. SLE subjects had a mean of $9.0 \pm 1.3 \%( \pm$ SEM) B1-bearing cells, while controls had $6.8 \pm 0.3 \%$. There was no difference in the number of B1bearing cells between the SLE subsets. Hyperresponders had an average of 9.2 $\pm 1.2 \%$ B1-positive cells compared to $8.8 \pm 2.3 \%$ in the normal-responding SLE group. There was a slight decrease in the number of Ig-bearing cells in the SLE group compared to controls, with no differences between SLE subsets. Those with an increased response to IFN- $\gamma$ had a mean of $6.7 \pm 1.2 \%$ Ig-bearing cells, while normal responders had an average of $6.9 \pm 1.8 \%$. Controls averaged $9.2 \pm$ $1.4 \%$ Ig-bearing cells per preparation.

TABLE 2

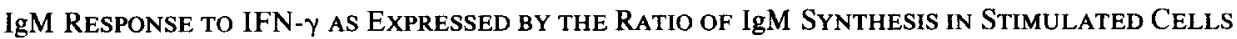
COMPARED to Resting CELlS

\begin{tabular}{cc}
\hline Subjects $(n)^{a}$ & IgM stimulation index $^{b}$ \\
\hline SLE (19) & $22.8+15.5$ \\
Group A (10) & $39.4 \pm 29.1$ \\
Group B (9) & $4.2 \pm 2.6$ \\
Control (8) & $3.7 \pm 1.5$
\end{tabular}

\footnotetext{
${ }^{a} n$ represents the number of subjects tested.

${ }^{b}$ The IgM stimulation index is the ratio of IgM produced by stimulated cells/resting cells. The results are expressed as the mean \pm SEM.
} 
TABLE 3

Percentage of B1-Bearing Cells and Ig-Bearing Cells in Venous Blood of SLE Subjects AND CONTROLS

\begin{tabular}{ccc}
\hline Subjects $(n)^{a}$ & \% B1-bearing cells & \% Ig-bearing cells $^{b}$ \\
\hline SLE (14) & $9.0 \pm 1.3$ & $6.8 \pm 1.1$ \\
Group A (7) & $9.2 \pm 1.2$ & $6.7 \pm 1.2$ \\
Group B (7) & $8.8 \pm 2.3$ & $6.9 \pm 1.8$ \\
Normals (11) & $6.8 \pm 0.3$ & $9.2 \pm 1.4$ \\
\hline
\end{tabular}

\footnotetext{
${ }^{a} n$ represents the number of subjects.

${ }^{b}$ The percentage of $\mathrm{B1}$ - and Ig-bearing cells was determined by flow cytometry. The results are expressed as the mean \pm SEM.
}

To determine whether the rosetting step altered the percentage of B cells such that non-T cells from the hyperresponding lupus subset had relatively more $B$ cells than the other groups, non-T cells from four hyperresponders, three normalresponder lupus patients, and three normal controls were stained with B1-FITC and analyzed with the flow cytometer. The percentage of B1-bearing cells in the non-T preparations from the hyperresponding subset was $43.8 \pm 13.1$ (mean \pm SEM) while the normal-responding subset was $47.6 \pm 14.8$, and the normal controls $51.9 \pm 7.2$. These results demonstrate that the rosetting step did not lead to a significant increase in the percentage of B cells in the hyperresponsive subset.

Comparison of disease activity with response to IFN- $\gamma$. We recorded an assessment of disease activity for 16 SLE patients in order to test whether disease activity influenced the response to IFN- $\gamma$. Since subjects taking greater than $5 \mathrm{mg}$ of prednisone a day were excluded from study, the study group was biased toward those with inactive disease, those with milder manifestations for which corticosteroids were not indicated, or in two instances, those with active disease immediately prior to the administration of high-dose corticosteroids. Subjects from the two SLE subsets were being treated similarly with regard to nonsteroidal anti-inflammatory and anti-malarial medications. Figure 2 compares disease activity and the rise in IgG in response to IFN- $\gamma$. In the subjects tested in this study, there was no correlation between disease activity and response to IFN- $\gamma$. Increased responsiveness to IFN- $\gamma$ was noted in patients with both active and inactive disease. In addition, several subjects with very active disease responded to IFN- $\gamma$ in the same way as controls.

Response of purified $B$ cells to IFN- $\gamma$. To test whether IFN- $\gamma$ directly stimulated $B$ cells or required macrophages, adherent cells were depleted from the non- $T$ cells by adherence to plastic petrie dishes. The adherence was performed twice to assure depletion of monocytes, and then the B cells were cultured with IFN- $\gamma$, using $10^{5}$ cells per well. When the IFN- $\gamma$-induced IgM response by B cells from three hyperresponders and threc normal responders was studied, no IgM synthesis was detected. The IgG response in the same subjects was minimal, with one subject from each group producing less than a twofold increase in IgG. The other four subjects demonstrated no response (data not shown). Since Ig syn- 


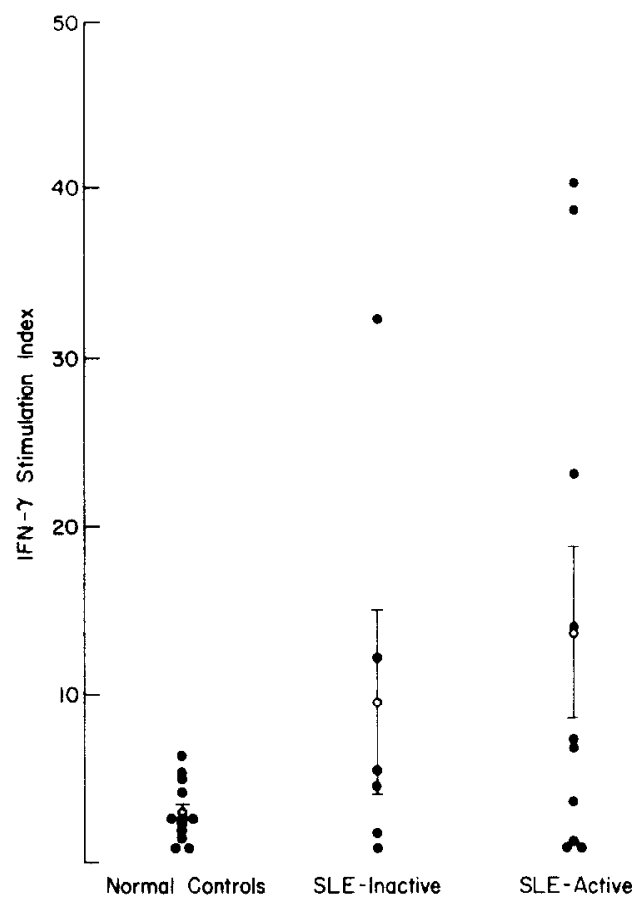

FIG. 2. Comparison of disease activity with the IgG response to IFN- $\gamma$. Disease activity was scored on a 0 to 3 scale according to the method of Barada (17). Disease activity is plotted against the IgG response to IFN- $\gamma$, recorded as the ratio of IgG production in stimulated cells/resting cells (stimulation index).

thesis by $B$ cells usually requires $T$ cells and $M \emptyset$, the small amount of IgG synthesized by these B cells most likely represents preactivated B cells or possibly the presence of small numbers of contaminating $\mathrm{T}$ cells and $\mathrm{M} \emptyset$. These data suggest that monocytes are required for the B-cell response to IFN- $\gamma$, but further studies will be required to determine whether monocytes, B cells, or other, unidentified cells are responsible for the hyperresponsiveness observed.

HLA-typing in patients with SLE. In order to examine whether the increased immunoglobulin response to IFN- $\gamma$ was linked to the major histocompatibility complex (MHC), 18 of the lupus patients were serotyped at HLA A, B, C, and D loci. A statistically significant increase in HLA-Cw7 was found in the SLE population relative to controls, with a predominance in the group hyperresponsive to IFN- $\gamma$. Twelve of eighteen SLE patients tested $(67 \%)$ had the $\mathrm{Cw} 7$ antigen $(P<$ 0.01). HLA-Cw7 was predominantly found in the SLE subjects who demonstrated an increased response to IFN- $\gamma$. Eight of nine hyperresponders (89\%) were positive for $\mathrm{Cw} 7(P<0.005$, relative risk $=18.9)$. Four of nine subjects (44\%) in the normal-responding SLE subset possessed the Cw7 antigen. This percentage is similar to the $30 \%$ frequency of the $\mathrm{Cw} 7$ antigen in the University of Michigan patient population. These results demonstrate that an increased response to IFN- $\gamma$ may be associated with the $\mathrm{Cw} 7$ allele. 


\section{DISCUSSION}

This study demonstrates that lymphocytes from approximately $50 \%$ of subjects with SLE show an increased responsiveness to a helper signal, IFN- $\gamma$. In addition, we demonstrated an association of HLA Cw7 with SLE, especially in those with an increased response to IFN- $\gamma$. The increased responsiveness to IFN- $\gamma$ was observed on cell populations depleted of $\mathrm{T}$ lymphocytes, suggesting that the action of IFN- $\gamma$ is on B cells or macrophages. Recent work by three groups of investigators has shown that IFN- $\gamma$ can function as a B-cell differentiation factor. In these studies, induction of active immunoglobulin secretion occurred via the direct interaction of IFN- $\gamma$ and B cells, without involvement of other cell types or signals $(11,12)$. However, in the studies presented here, IFN- $\gamma$ failed to activate purified B cells from the hyperresponsive group, suggesting that this is probably not the mechanism. In more recent reports, IFN- $\gamma$ and IL-2 were shown to be synergistic in inducing B-cell differentiation to antibody-secreting cells $(28,29)$, suggesting that $\mathrm{T}$ cells may be involved in the B-cell hyperresponsiveness observed in this report. However, $\mathrm{T}$ cells were depleted from our lymphocyte preparation, making this mechanism less likely, although a few remaining $\mathrm{T}$ cells could theoretically support this mechanism. Our observation that depletion of adherent cells abrogates the IFN- $\gamma$-induced antibody response suggests that adherent cells are required for the hyperresponsiveness observed in lymphocytes from some lupus patients, and may be the cells responsible for the hyperresponsiveness. The macrophage may be acting via secreted IL-1, which is involved in B-cell activation (30), or the IL-1 may act on a smaller number of remaining $\mathrm{T}$ cells to induce IL-2 secretion (31). The observation that IFN- $\gamma$ augments specific B-cell responses through a $\mathbf{M} \emptyset$-dependent process supports these hypotheses (32). Yet another mechanisms for the increased response is suggested by the data of Romagnani et al. (33), who reported that IFN- $\gamma$ also has B-cell growth-factor activity. These findings would imply that the augmented Ig response in the hyperresponsive subset may reflect production of a greater number of B cells in vitro, resulting in an augmented Ig response. Further studies will be required to determine the precise role of $M \emptyset$ and $T$ cells in the augmented Ig response observed.

Since subjects on greater than $5 \mathrm{mg}$ per day of prednisone or cytotoxic agents were excluded from study, the study group was biased toward patients with inactive disease or with milder manifestations for which corticosteroids were not indicated. In this population there was no correlation of hyperresponsiveness with disease activity. Subjects with both inactive and active disease demonstrated increased IFN- $\gamma$ responsiveness. Similarly there was no correlation between response to IFN- $\gamma$ and any clinical or laboratory manifestation of SLE. These data indicate that hyperresponsiveness is not due to disease activity.

Other possibilities for the increased IFN- $\gamma$ response include increased numbers of B cells in the hyperresponsive SLE subset or increased preactivation of B cells in that group. We have demonstrated that the number of B cells is similar in PBMC as well as the non-T population from the two SLE subsets and normal controls, excluding the possibility that increased numbers of B cells are the reason for the observed differences. Possibly the increased responsiveness is due 
to increased preactivation or "priming" of B cells in vivo. However, while both groups of SI.F patients have increased resting production of immunglobulins indicating preactivation, there was no difference in the resting immunoglobulin production between the two subsets to indicate greater in vivo activation of the hyperresponsive group. Furthermore, IFN- $\gamma$ can act as a BCDF on activated but not on unstimulated B cells $(28,29)$. The observation that IFN- $\gamma$ did not stimulate purified SLE B cells further supports the concept that B-cell preactivation is not responsible for the hyperresponsiveness. In addition there was no difference in B-cell IL-2R expression between the two lupus groups. By these criteria the state of activation of the $B$ cells in each SLE subset is similar and does not account for the observed differences in response to IFN- $\gamma$.

This study also demonstrates an association of HLA-Cw7 with SLE, in agreement with an observation recently made by other investigators (34). More specifically, an association was detected between the $\mathrm{CW} 7$ allele and SLE subjects who demonstrated an increased response to IFN- $\gamma$. Interestingly, HLA-Cw 7 is in linkage disequilibrium with both HLA-DR2 and DR-3, serotypes previously associated with SLE $(35,36)$. Because of the small number of patients studied, additional studies need to be performed to confirm the association presented here. If further work confirms that HLA-Cw7 is seen in higher frequency in SLE patients than is HLA DR-2 or DR-3, it would suggest that this marker may be linked more tightly to a gene or genes present in patients with SLE. Recent work by Rashidbaigi and colleagues has indicated that the gene for the IFN- $\gamma$ receptor is localized to chromosome 6 (37). Because the MHC is also present on the sixth chromosome, the association of $\mathrm{CW} 7$ and an increased response to IFN- $\gamma$ takes on increased relevance.

IFN has been shown to be increased in patients with SLE (38-41). However, Preble has identified this IFN as IFN- $\alpha$, although it was a peculiar acid-labile form, like IFN- $\gamma(41)$. Studies by Sibbitt and colleagues have also demonstrated that the pathway of IFN- $\gamma$ production is normal in patients with SLE and not excessively activated (42). These observations suggest that IFN- $\gamma$ production is normal in SLE patients, and the immune defect may lie in the response to normal amounts of B-cell differentiation signals.

In conclusion, this study demonstrates that a subset of patients with SLE has lymphocytes which show increased responsiveness to a helper signal, IFN- $\gamma$. The precise mechanism responsible for this hyperactivity is uncertain. It is well known that environmental factors such as uv light, viral infections, and certain chemicals and drugs can trigger disease activity in SLE patients. Viral infections are known to induce large amounts of interferons and other lymphokines, leading to a cascade of reactions in humoral and cellular responses. Patients with a predetermined hyperresponsiveness to these regulatory signals could potentially overproduce immunoglobulins, autoantibodies, and immune complexes, leading to the lupus state. Given the observations with IFN- $\gamma$, it is possible that this family of immunoregulatory molecules may contribute to the development and perpetuation of SLE. Further work on the mechanism of action of IFN- $\gamma$ on SLE lymphocytes may lead to an increased understanding of the pathogenesis of this disease. 


\section{ACKNOWLEDGMENTS}

We thank Genentech for supplying the intereferon- $\gamma$ used in these experiments. We also thank Shelley Troxell and Carol Kaczmarek for their expert secretarial assistance.

\section{REFERENCES}

1. Fauci, A. S., and Moutsopoulos, H. M., Arthritis Rheum. 24, 577, 1981.

2. Budman, D. R., Merchant, E. B., Steinberg, A. D., et al., Arthritis Rheum. 20, 829, 1977.

3. Blaese, R. M., Grayson, J., and Steinberg, A. D., Amer. J. Med. 69, 345, 1980.

4. Bresnihan, B., and Jasin, H. E., J. Clin. Invest. 59, 106, 1977.

5. Fauci, A. S., Steinberg, A. D., Haynes. B. F., and Whalen, G., J. Immunol. 121, 1473, 1979.

6. Sagawa, A., and Abdou, N. I., J. Clin. Invest. 63, 536, 1979.

7. Krakauer, R. S., Clough, J. D., Frank, S., and Sundeen, J. T.. Clin. Immunol. Immunopathol. 14, 333, 1979.

8. Gattringer, C., Huber, H., Michlmayr, B., and Braunsteiner, H., Immunobiology 163, 52, 1982.

9. Nakamura, Z., Asano, T., Yano, K.. and Ofuji, T., Clin. Immunol. Immunopathol. 24, 82, 1982.

10. Theofilopoulos, A. N., and Dixon, F. J., Adv. Immunol. 37, 269, 1985.

11. Leibson, H. J., Gefter, M., Zlotnick, A., Marrack, P., and Kappler. J. W., Nature (London) 309, 801, 1984.

12. Sidman, C. L., Marshall, J. D., Shultz. L. D., Gray, P. W., and Johnson, H. M., Nature (London) $309,807,1984$.

13. Walker, S. E., Clin. Immunol. Immunopathol. 8, 212, 1977.

14. Heremans, H., Billiau, A., Colombatti. A., Hilgers, J., and DeSomer, P., Infect. Immun. 21, 930, 1978.

15. Sergiescu, D., Cerutti, I., Efthymiou, E., Kahan, A., and Chany, C., Biomedicine 31, 51, 1979.

16. Tan, E. M., Cohen, A. S., Fries, J. F., Masi, A. T., McShane, D. J., Rothfield, N. F., Schaller. J. G., Talal, N., and Winchester, R. J., Arthritis Rheum. 25, 1277, 1982.

17. Barada, F. A.. Jr., Andrews, B. S.. Davis. J. S., IV, and Taylor, R. P. Arthritis Rheum. 24, 1244, 1981.

18. Richardson, B., Kahn, L., Lovett, E. J., and Hudson, J., J. Immunol. 137, 35. 1986.

19. Richardson, B., Hum. Immunol. 17, 456, 1986.

20. Gadeberg, O. V., Rhodes, J. M., and Larsen, S. O., J. Immunol. Methods 31, 10, 1979.

21. Engvall, E., In "Methods in Enzymology" (H. Van Vunakis and J. J. Langone, Eds.), Vol. 70, p. 438. Academic Press, New York, 1980.

22. Loken. M. R., and Lanier, L. L., Cytometry, 5, 158, 1984.

23. Mittal, K. K., Mickey, M. R., Singal, E. R., and Terasaki, P. I., Transplantation 6, 927, 1968.

24. Lowry. R., Goguen, J., Carpenter, C. B., Strom, T. B., and Garovoy, M. R.. Tissue Antigens 14, 330, 1979.

25. Teraski, P. I. (Ed.), "Histocompatibility testing." UCLA Tissue Typing Lab, Los Angeles, 1980.

26. Noma. T., and Dorf. M. E., J. Immunol. 135, 3655, 1985.

27. Frasca, D., Adorini, L., Landolfo, S., and Dorin, G., J. Immunol. 134, 3907, 1985.

28. Nakagawa, T., Hirano, T., Nakagawa, N., Yoshizaki, K., and Kishimoto, T., J. Immunol. 134, 959, 1985.

29. Nakagawa, T.. Nakagawa, N., Goldstein, H., Volkman, D. J., and Fauci, A. S., J. Immunol. 137, 3175, 1986.

30. Howard, M., Mizel, S. B., Lachman, L., Ausel, J., Johnson, B., and Paul, W. E., J. Exp. Med. $157,1543,1983$.

31. Smith. K. A.. Lachman, L. B., Oppenheim, J. J., and Favata, M. F., J. Exp. Med. 151, 1556, 1980.

32. Nakamura, M., Mansen, T., Pearson, G. D. N., Dalay, M. J., and Gefter, M. L., Nature (London) 307, 381, 1984.

33. Romagnani, S., Giudizi, M. G., Biagiotti, R., Almerigogna. F., Miugari. C., Maggi, E., Liang. C.-M., and Moretta, L., J. Immunol. 136, 3516, 1986.

34. Ballou, S. P., Khan, M. A., Kushner, 1., Zachary, A., and Braun. W. E., Clin. Res. 32, 755A (abstract), 1984. 
35. Celada, A., Barras, C., Benzonana, G., and Jennet. M., Tissue Antigens 15, $288,1978$.

36. Gladman, D. D.. Terasaki, P. L., Park, M. S., Iwaki, Y.. Louie, S., Quismorio, F. P.. Barnett. E. V., and Leibling, M. R., Lancet 2, 902. 1979.

37. Rashidbaigi, A., Langer, J. A., Jung, V., Jones, C. Morse, H. G., Tischfield, J. A.. Trill, J. J. Kung, H., and Pestka, S., Proc. Natl. Acad. Sci. USA 83, 388, 1986.

38. Hooks, J. J., Moutsopoulos, H. M., Geis, S. A., Stahl, N. I., Decker, J. L., and Notkins, A. L.. N. Engl. J. Med. 301, 8, 1979.

39. Hooks, J. J., Jordan, G. W., Cupps, T., Moutsopoulos, H. M., Fauci, A. S., and Notkins, A. L.. Arthritis Rheum. 25, 400, 1982.

40. Preble, O. T., Black, R. J., Friedman, R. M., Klippel, J. H., and Vilcek, J., Science 216, 431. 1982.

41. Ytterberg, S. R., and Schnitzer. T. J., Arthritis Rheum. 25, 406, 1982.

42. Sibbitt. W. L., Kenny, C., Spellman, C. W., Ley, K. D., and Bankhurst, A. D., Clin. Immunol. Immunopathol. 32, 173, 1984.

Received May 11, 1987; accepted with revision August 3, 1987 